\title{
Hereditary functional individuality of semiconductor sensors
}

\author{
V.P.Migal, A.V.But, G.V.Migal, I.A. Klymenko \\ National Aerospace University "Kharkiv Aviation Institute", \\ 17, Chkalova str., Kharkiv, Ukraine, 61070
}

Received April 2, 2015

\begin{abstract}
By geometrisation of the natural and impurity bands of photocurrent spectrum of semiconductor sensors in the parameter space it is shown that individual features in their structures are technologically inherited. In analysis of the natural and impurity photocurrent bands the universal differential-geometric parameters and indicators of integrative energy balance of photo-induced processes are applied. To analyze the structure of the photosensitivity bands the matrix of balance indicators is proposed.

Keywords:photocurrent spectra, photodielectric response, transition photoresponse, photocurrent spectrum signature, technologically inherited.

Посредством геометризации собственной и примесной полос спектра фототока полупроводниковых сенсоров в параметрическом пространстве показано, что индивидуальные особенности их структуры технологически унаследованы. При анализе собственных и примесных полос фототока применялись универсальные дифференциально-геометрические параметры и интегративные показатели энергетического баланса фотоиндуцированных процессов. Для анализа структуры полос фоточувствительности предложена матрица показателей сбалансированности.
\end{abstract}

Спадкова індивідуальність функціонування напівпровідникових сенсорів. В.П.Мигаль, А.В.Бут, І.А.Клименко, Г.В.Мигаль.

За допомогою геометризації власної та домішкової смуг спектра фотоструму напівпровідникових сенсорів у параметричному просторі показано, що індивідуальні особливості їх структури технологічно успадковані. При аналізі власної і домішкової смуги фотоструму застосовувалися універсальні диференціально-геометричні параметри і інтегративні показники енергетичного балансу фотоіндукованих процесів. Для аналізу структури смуг фоточутливості запропонована матриця показників збалансованості.

\section{Introduction}

Common technological and operational problems (control, identification, classification, calibration, etc.) are inherent to physical, chemical and biological sensors [1]. For semiconductor sensors, based on $\mathrm{A}^{2} \mathrm{~B}^{6}$ compounds, solution of these problems is constrained by insufficient study of the effect of growth conditions and dynamics of aftercrystallization cooling under formation and evolution of defect-structured ensemble (DSE) [2]. Ordered distribution of the de- fects determines unique photoelectric and others properties [3]. Spatially inhomogeneous distribution of the defects leads to appearance of the defects clusters and complex energy spectrum of the electron states [4]. Furthermore, dispersion of the sensor parameters arises, that creates a diagnostic and operational problems. In particular, sensors of any nature have operation individuality which is usually appeared in dynamic features of their functional characteristics. So, the operation of the semicon- 
ductor sensor has its subtle dynamic, energetic and informational aspects which determine the kinetic hidden features of sensor photocurrent (PhC) spectrum and others characteristics [5, 6]. Therefore, the solving of many operational and other problems we see in finding the means of identifying and analyzing of the technologically inherited individuality. However, existing approaches are insufficiently useful for identifying of subtle features of characteristics and for the analysis of their impact on the individuality of the sensor operation.

Geometrization of functional characteristics of the $A^{2} B^{6}$ crystals (absorption bands in the form of the Arganda digramm [7], bands photodielectric response in the form of diagrams of complex permittivity [8], the bands of the photoelectric response in the form of 1st order signatures [9]) revealed that individuality of characteristics related with dynamic and statistical ordering of the photo-induced processes. The ordering of the subtle features of the transition photoresponse (PhR) of zinc chalcogenides appears usually in signatures 1st and 2 nd order. They consist of closed sequences of geometrically ordered portions which differ in length, slope or curvature [10]. It is important that geometric similarity of the portions of transient PhR combine with the individuality of their distribution in the signature configuration [11]. Idea that the signature area $S$ of the transition $\mathrm{PhR}$ as power of subset of possible photoinduced dynamic microstates can detect and evaluate the orderliness of transition PhR statistically. So, from the microscopic point of view, the number of possible quantum states of $W$ can be considered as statistical weight [12]. Entropy $H$, which is proportional to the natural logarithm of $W$, that is $\mathrm{H} \propto \ln W$, statistically characterizes the order of the microstates distribution. Entropy is a sensitive parameter to the external and internal factors. Dynamic ordering is also evident in the balancing of antiphase processes in the PhR, which displays area ratio upper $S_{u}$ and lower $S_{l}$ parts of the signature $B_{d y n}=S_{u} / S_{l}$ [13]. Thus, violation of the balance $V_{d y n}$ of transition PhR of sensors during their operation in extreme conditions is accompanied by decrease in the dynamic ordering, as well as by appearance of instability and artifacts.

Statistical ordering of DSE is a natural reaction of the piezo-electric crystals $A^{2} B^{6}$ for maximum counteraction to external disturbances in the growth process and forced cooling of the crystal boule. Dynamic ordering of electronic subsystem occurs during photoexcitation and appears in the signature configuration of sensor transitional PhR $I(t)-d I / d t$ [15]. Obviously the statistical and dynamic orderings are interrelated. This is evidenced by the dependence of the configuration of the signature on the the photoexcitation wavelength. Consequently, there is a causal relation between the dynamic and energetic aspects of the sensor operation. It can be assumed that this relation defines inherited informational aspects which determine the operation scenario of sensor. The main purpose of the work is the further development of universal approach, which aims to identification of the individual scenario of operation of different nature sensors.

\section{Experimental}

As objects of research ZnSe crystals were chosen and sensors based on them. ZnSe crystals were grown from melt by the modified Bridgman method of vertical crystallization. The samples had the rectangular parallelepiped form with dimensions of $10 \times 10 \times 3 \mathrm{~mm}^{3}, 12 \times 6 \times 4 \mathrm{~mm}^{3}$. Their resistivity was $\rho \geq 10^{12} \mathrm{Ohm} \cdot \mathrm{cm}$. Structural research have discovered defects of different types and sizes in the samples. Their diversity and complexity of the distribution determine the individual technology-inherited defect structure and complex energy spectrum. The indium-gallium contacts were created on the greatest opposite sides of the samples. Measurements of $\mathrm{PhC}$ spectrum of the crystals and the PhC kinetic $I(t)$ were carried out under field strength $E \sim 3 \cdot 10^{2} \mathrm{~V} \cdot \mathrm{cm}^{-1}$ and temperature of $293 \mathrm{~K}$. For separation of the subtle dynamic features $\mathrm{PhC} I(t)$ signal are digitized at the sampling rate $f_{d}>10^{3} \mathrm{~Hz}$ using the data collection system ADVANTECH PCI-1711L, followed by treatment with a computer. Processing of $\mathrm{PhR}$ and determination of the differential-geometric parameters of his signatures on the phase plane are implemented in the software package Octave.

For most of the investigated crystals, that were cooled naturally after crystallization, the $\mathrm{PhC}$ spectrum consists of the natural photosensitivity band ( $\max 468 \mathrm{~nm}$ ), which dominates over the impurity photosensitivity band (530 nm) ( Fig. 1, curve 1). In the crystals, that were cooled forcibly after crystallization, the vice versa impurity photosensitivity band with maximum $498 \mathrm{~nm}$ dominates in the $\mathrm{PhC}$ spectrum (Fig. 1, curve 2). The bands in the $\mathrm{PhC}$ spectra are well reproduced. 


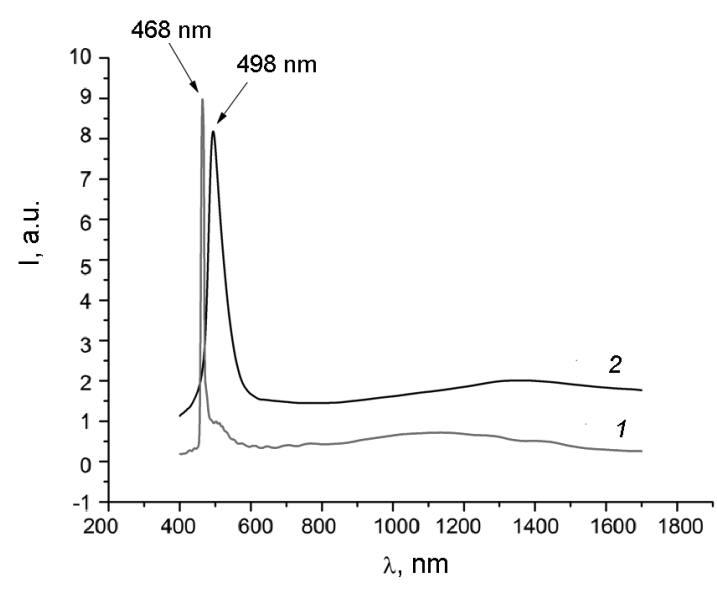

Fig. 1. Photocurrent spectra of ZnSe crystals (1 - crystal was cooled naturally, 2 - crystal was cooled forcibly).

The PhC spectra of many of investigated ZnSe crystals contain not yet clearly defined 1-2 impurity IR bands, the position of which depends on the speed and direction of scanning of spectrum. Coarse and subtle features of the PhC spectrum are clearly discernible at signatures of $1^{\text {st }} I(\lambda)-$ $d I(\lambda) / d \lambda$ and $2^{\text {nd }} \quad d I(\lambda) / d \lambda-d^{2} I(\lambda) / d \lambda^{2}$ order. Signatures $I(\lambda)-d I(\lambda) / d \lambda$ and $d I(\lambda) / d \lambda-d^{2} I(\lambda) / d \lambda^{2}$ are the projections of the trajectory of the photoinduced energy states (Fig. 2b, a, b, c plane) on the orthogonal planes. Comparison of configurations of the PhC spectra signatures of 1 st and 2 nd order of naturally cooled and forcibly cooled samples (Fig. 2b), shows their essential difference.

As can be seen from Fig. 2, the configuration of all signatures of natural and impurity $\mathrm{PhC}$ bands consist of individual sequences of geometrically-ordered parts. The individuality of signatures appears in amount of components-parts, their length, and are also characterized by differential geometric parameters (slope $d I(\lambda) / d \lambda$ and curvature $\left.d^{2} I(\lambda) / d \lambda^{2}\right)$. Their physical meaning is different and depends on the chosen model. It is important that the transformation of the PhC spectrum as signature of the 1 st and 2 nd order made natural decomposition of the $\mathrm{PhC}$ spectrum into its components. Herewith the individuality and subtle features of natural and impurity $\mathrm{PhC}$ bands most appear in the signature $d I(\lambda) / d \lambda-d^{2} I(\lambda) / d \lambda^{2}$. It is located in 4 quadrants of the plane $(d I(\lambda) / d \lambda$, $\left.d^{2} I(\lambda) / d \lambda^{2}\right)$, that allows to analyze the structure of relations between the main components of the $\mathrm{PhC}$ band.

\section{Results and discussion}

As can be seen from Fig. 2, the signatures of the $1 \mathrm{st}$ and $2 \mathrm{nd}$ order of the $\mathrm{PhC}$ spectrum are orthogonal projections of trajectory of the photoinduced energy states in the parameter space $\{I(\lambda), \quad d I(\lambda) / d \lambda$, $\left.d^{2} I(\lambda) / d \lambda^{2}\right\}$. The trajectory displays the scan of energy spectrum of the localized crystal states. The PhC spectra of the crystals were scanned at the same speed $d \lambda / d t$ to obtain the trajectory. As can be seen from Fig. 2, after such conversion of the $\mathrm{PhC}$ spectrum of ZnSe crystals in the signature of the $1^{\text {st }}$ and $2^{\text {nd }}$ order the geometrically-ordered components-parts stand out and the hidden relations between them made available for analysis. Indeed, at projections of the "trajectory" spatio-temporal correlations appear in the form of similarity of the individual signatures components. It is possible to analyze the spatial and temporal correlation of components of natural and impurity $\mathrm{PhC}$ bands from three complementary points of view using the signatures $I(\lambda)-d I(\lambda) / d \lambda, \quad I(\lambda)-d^{2} I(\lambda) / d \lambda^{2} \quad$ and $d I(\lambda) / d \lambda-d^{2} I(\lambda) / d \lambda^{2}$. The configurations of these signatures have complementary information about the features: a) structure of the PhC spectrum of sensor, b) influence of the internal fields on the energy spectrum of defects; c) relationship between the dynamic and energetic subtle features which determine the informational aspects of the sensor operation. It is important that the differential-geometric parameters of the bands components can be associated with the physical parameters of the photo-induced processes. It should be note the high sensitivity of the parameters and entropy to the technology of thermal, mechanical and chemical treatment of the crystal.

The photodielectric response spectrum of these crystals represented as complex permittivity diagramms consist of closed sequence of arcuate parts. They cover an area that can be represented as subset power of the photo-induced states [4]. Following the analogy, the area of the signature can also be represented as power of subset of the energy states. Not clear borders of the parts in signatures of the 1st order $i$ point at influence of the internal field on the photo-induced processes. Configuration of the signature of the impurity band indicates its complex energy structure. It identifies by the ways: scanning photodielectric spectroscopy [14], the discrete wavelet transform [15].

Short-wave and long-wave parts of the natural $\mathrm{PhC}$ band at configuration of the 

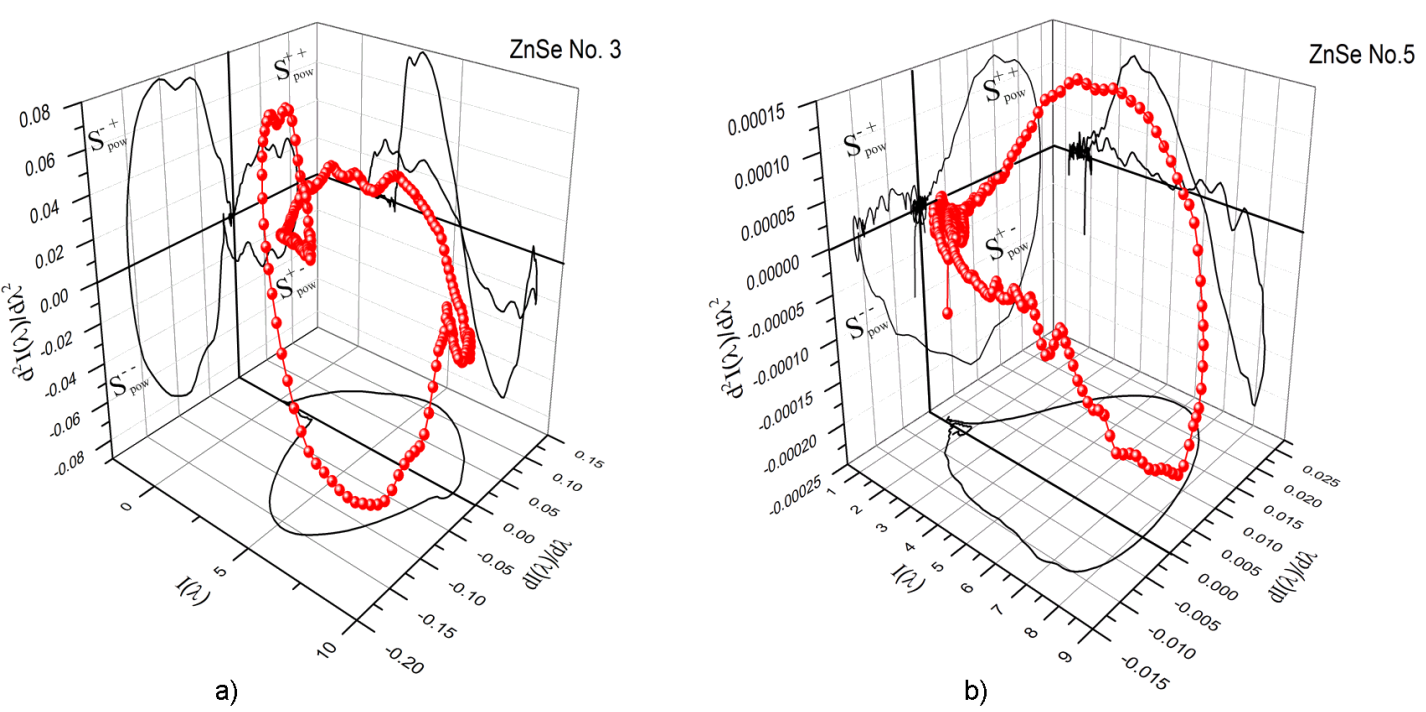

Fig. 2. Photocurrent spectrum signatures of the 1st and 2nd order of zinc selenide crystals (a No.3 - crystal was cooled naturally and b - No.5 - crystal was cooled forcibly).

signature $I(\lambda)-d^{2} I(\lambda) / d \lambda^{2}$ are similar. Obviously, this similarity indicates the balance of generation-recombination processes. We also note the presence of the subtle features in the long-wave band. Asymmetric signature $I(\lambda)-d^{2} I(\lambda) / d \lambda^{2}$ extremes are typical for the impurity $\mathrm{PhC}$ band. The asymmetry shows the imbalance of photoinduced processes (capture / release of carriers, relation of transfer parameters from the wavelength, etc.). Increase of the imbalance by increasing the electric field intensity in some samples is accompanied by a local instability.

In configurations of signatures of the 2nd order the main components of $\mathrm{PhC}$ bands are naturally spatially separated. Scanning of these bands converts them in the original energy cycle. They display the nature of the relationship between $d I(\lambda) / d \lambda$ and $d^{2} I(\lambda) / d \lambda^{2}$ during the scanning band of the $\mathrm{PhC}$ spectrum that is energy cycle of the sensor operation. In this cycle, individuality of the natural and impurity bands of photosensitivity mostly reveals. As can be seen from Fig. 2a, the configuration of signature of the natural band, as the operation cycle is symmetric. It may indicate the natural balance of the generation-recombination processes. As expected the influence of DSE is mostly appeared in the scan cycle of impurity band of the PhC spectrum.

Obviously, in technological heredity the general Curie principle of symmetry plays an important role - if certain reasons cause the corresponding effect, the elements of symmetry of the causes must be appeared in the effects, caused by them. The characteristic features of the scan cycle of the impurity $\mathrm{PhC}$ band of the crystals, i.e. signatures $d I(\lambda) / d \lambda-d^{2} I(\lambda) / d \lambda^{2}$, indirectly confirm it. These include: a) asymmetry of the scanning cycle, which depends on the speed of scanning of the spectrum and the crystal photoactive history; b) imbalance opposing processes in the cycle; c) the localization of the subtle features in one quadrant of the energy cycle of the $\mathrm{PhC}$ spectrum scanning. Therefore, we can assume that in the energy scan the cycle of the impurity $\mathrm{PhC}$ band of the crystals appears by the influence of many factors (the relationship of electrically active defects, their distribution in spatially inhomogeneous field of residual stresses, etc.). Hidden relationships in the impurity band of the PhC spectrum determine the configuration of the signature, which may serve as natural model of structure of the energy operation cycle of the sensor. Universal balance indicators of operation $B_{i j}$, that were used in the analysis of the geometric model of temporary transitional $\mathrm{PhR}$ [11], are suitable to analyze the model. The energy balance of the operation cycle can be characterized by dimensionless parameters between its main components. They are equal to ratio of the area of all quadrants of the signature together $B_{12}=S_{\text {pow }}{ }^{+-} / S_{\text {pow }}{ }^{++}$, etc. In square matrix of indicators (see Table) it appears: a) individuality and the ordering of the energy cycle of the sensor operation; b) symmetry or asymmetry of the operation cycle; c) the balance - imbalance opposite-cycle processes; d) individuality of the main components of the operation cycle. The matrix of the balance indicators can serve as a kind of sensors "passport", that can be used to simplify 
Table 1. The matrix of the indicators of energy balance of sensor operation cycle.

\begin{tabular}{|c|c|c|c|c||}
\hline Quadrants & $"++"$ & $"+-"$ & $"--"$ & $"-+"$ \\
\hline$"++"$ & 1 & $S_{p o w}^{++} / S_{p o w}^{ \pm}$ & $S_{p o w}^{++} / S_{p o w}^{--}$ & $S_{p o w}^{++} / S_{p o w}^{-+}$ \\
\hline$"+-"$ & $S_{p o w}^{ \pm} / S_{p o w}^{++}$ & 1 & $S_{p o w}^{ \pm} / S_{p o w}^{--}$ & $S_{p o w}^{ \pm} / S_{p o w}^{-+}$ \\
\hline$"--"$ & $S_{p o w}^{--} / S_{p o w}^{++}$ & $S_{p o w}^{--} / S_{p o w}^{ \pm}$ & 1 & $S_{p o w}^{--} / S_{p o w}^{-+}$ \\
\hline
\end{tabular}

identification, classification and search of identical sensors. In fact, the balance indicators $B_{i j}$ and their relationships represent the informational aspects of the energy cycle of the sensor operation, that is technologically inherited.

Obviously, that inherited technologically DSE ordering affect on the character of distribution of photosensitivity centers in the crystalline matrix. This is confirmed by the investigations results of transformation of PhR signatures of the crystals, which were exposed to acoustic treatment on the frequency of the natural elastic vibrations. For example, high sensitivity of signature configuration to the technological crystal treatment regimens indicates an inherited scenario of the sensor operation. It displays the photo-induced processes (reorganization of spatially inhomogeneous internal elastic and electric fields of defects, recharging of sophisticated centers and others). Thus, as an example of geometrisation of the spectral $\mathrm{PhC}$ bands in the parameter space and analysis of their structure the dynamic and energy features of the photoinduced processes were allocated. The relationship of these features determines the operation cycle of the sensor. The matrix of energy balance indicators is proposed for analysis of the information aspects of the cycle.

\section{Conclussion}

In general, the approach can reveal the subtle features of other functional characteristics of the sensor, as well as it can be used to analyze the signals of different type of sensors using universal indicators. It should be noted Note that the further development of the approach and its application to system analysis of results of complex investigation of different type sensors allows us to solve the complex technological, operational and diagnostic problems. In particular, sufficiently high sensitivity of differential-geometry and integral indicators of signatures of the sensor PhR to the in- ternal and external factors is promising to control the functional characteristics at all stages of the life cycle of the sensor, as well as for monitoring and forecasting their performance. The approach is also of interest to research the dynamic behavior of different types of sensors, including chemical and biological in the extreme conditions.

This study was supported by the State Foundation for Basic Research of Ukraine.

\section{References}

1. Ya.I.Lepikh, Yu.E.Gordienko, S.V.Dzyadevych et al., Creation of Microelectronic Transducers of New Generation for Intellectual Systems, Astroprint, Odessa (2010) [in Ukrainian].

2. V.Komar, A.Gektin, D.Nalivaiko et al., Nucl. Instr. Meth.Phys. Res., 458, 113 (2001).

3. I.G.Gavrikova, V.P.Migal, A.L.Rvachev, Phys. Stat.Sol.(a), 37, K21 (1976).

4. V.P.Migal, Semiconductors, 35, 1135 (2001).

5. A.V.But, V.P.Mygal, A.S.Phomin, Techn. Phys., 57(4), 575 (2012).

6. V.P.Mygal, A.V.But, O.O.Smatko, I.V.Bodnar, Functional Materials, 19, 555 ( 2012).

7. V.V.Sobolev, V.V.Nemoshkalenko, Methods of Computational Physics in the Solid State Theory. The Electronic Structure of Semiconductors, Naukova Dumka, Kiev (1988) [in Russian].

8. I.A.Klimenko, V.K.Komar', V.P.Migal', D.P.Nalivaiko, Semiconductors, 35, 135 (2001).

9. V.P.Mygal, A.V.But, O.O.Smatko, I.V.Bodnar, Functional Materials, 19, 555 (2012).

10. A.V.But, V.P.Mygal, I.V.Bodnar, Semiconductors, 48, 163 (2014).

11. V.P.Mygal, A.V.But, A.S.Phomin, I.A.Klimenko, Semiconductors, 49, 634 (2015).

12. A.Keith, Entropy. Amer. J. Phys., 52, 492 (1984).

13. A.V.But, V.P.Mygal, I.V.Bodnar, Optical Systems Design 2012, Proc. SPIE 8550, 85502B (2012).

14. A.V.But, V.P.Mygal, A.S.Fomin, Techn. Phys., 57, 575 (2012).

15. V.K.Komar, V.P.Migal, O.N.Chugai et al., Appl.Phys. Lett., 81, 4195 (2002).

16. A.V.But, V.P.Mygal, A.S.Phomin, Semiconductors, 43, 581 (2009). 